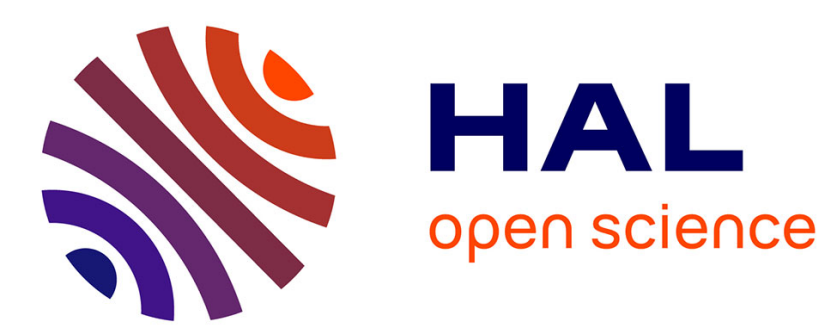

\title{
HETEROEPITAXIAL GROWTH OF TiO2, VO2, AND TiO2/VO2 MULTILAYERS BY MOCVD
}

H. Chang, Y. Gao, J. Guo, C. Foster, H. You, Tiantian Zhang, D. Lam

\section{To cite this version:}

H. Chang, Y. Gao, J. Guo, C. Foster, H. You, et al.. HETEROEPITAXIAL GROWTH OF TiO2, VO2, AND TiO2/VO2 MULTILAYERS BY MOCVD. Journal de Physique IV Proceedings, 1991, 02 (C2), pp.C2-953-C2-960. 10.1051/jp4:19912115 . jpa-00249794

\section{HAL Id: jpa-00249794 https://hal.science/jpa-00249794}

Submitted on 1 Jan 1991

HAL is a multi-disciplinary open access archive for the deposit and dissemination of scientific research documents, whether they are published or not. The documents may come from teaching and research institutions in France or abroad, or from public or private research centers.
L'archive ouverte pluridisciplinaire HAL, est destinée au dépôt et à la diffusion de documents scientifiques de niveau recherche, publiés ou non, émanant des établissements d'enseignement et de recherche français ou étrangers, des laboratoires publics ou privés. 
Colloque C2, suppl. au Journal de Physique II, Vol 1, septembre 1991 HETEROEPITAXIAL GROWTH OF $\mathrm{TiO}_{2}, \mathrm{VO}_{2}$, AND $\mathrm{TiO}_{2} / \mathrm{VO}_{2}$ MULTILAYERS BY
MOCVD

\author{
H.L.M. CHANG, Y. GAO J. GUO, C.M. FOSTER, H. YOU, T.J. \\ ZHANG and D.J. LAM \\ Materials Science Division, Argonne National Laboratory, \\ 9700 S. Cass Avenue, Argonne, IL 60439, U.S.A.
}

\begin{abstract}
Titanium and vanadium dioxide systems were selected to study the MOCVD process for the growth of oxide epitaxial films. Single-crystal $\mathrm{TiO}_{2}$ and $\mathrm{VO}_{2}$ films in single and multilayered configurations have been successfully grown on sapphire $\left(\alpha-\mathrm{Al}_{2} \mathrm{O}_{3}\right)$ single-crystal substrates. Seven distinct epitaxial orientation relationships between the films and the substrates were observed. Discussion on these epitaxial relationships based on the consideration of atomic arrangements of the materials is presented. From our experimental results, we concluded that single layer films (both $\mathrm{TiO}_{2}$ and $\mathrm{VO}_{2}$ ) were grown by the nucleations of three-dimensional clusters. Quantum mechanical calculations of the electronic structures, charge distributions, and energetics of the free substrate surfaces were performed and some results are presented.
\end{abstract}

\title{
Introduction
}

A great variety of oxide materials in thin-film form have been extensively used for various technological applications [1,2]. Almost all of these applications exploit the films in either polycrystalline or amorphous form. Thin oxide films in the form of single crystal are required for many potential applications. For example, to develop a fully integrated guided-wave optical system such as an integrated optical recording head [3] which incorporates laser sources, detectors, modulators, and passive components into a single chip of substrate, one needs to layer different oxide materials together not only in single-crystal form but also in controlled orientations. These requirements impose great challenges on the epitaxial oxide thin film growth techniques. Research work in this area has just begun [4].

In recent years, the metal-organic chemical vapor deposition (MOCVD) technique has experienced great success in preparing thin films of crystalline semiconductor materials in single and multilayered structures. Controlled growth at the atomic level is achievable now. Research in using this technique to grow metal oxides is expected to expand at a rapid pace because of the progress made in precursor chemistry in the past few years. Our long-term goal is to obtain controlled growth of high quality epitaxial oxide films in single and multilayered structures using the MOCVD technique. In this paper, we report some of the results obtained in our ongoing studies of growing single-crystal $\mathrm{TiO}_{2}$ and $\mathrm{VO}_{2}$ films as well as multilayer structures made of these two materials.

\section{Experimental}

The films were grown in a cold-wall horizontal low-pressure MOCVD system. Detailed description of the apparatus and the sample preparation procedure was given elsewhere [5]. The organometallic (OM) precursors used for titanium and vanadium were titanium isopropoxide $\left(\mathrm{Ti}\left(\mathrm{OC}_{3} \mathrm{H}_{7}\right)_{4}\right)$ and vanadium triethoxide oxide $\left(\mathrm{VO}\left(\mathrm{OC}_{2} \mathrm{H}_{5}\right)_{3}\right)$, respectively. High purity nitrogen was used as carrier gas and oxygen was used as oxidant. In our earlier works $[5,6]$, we found that within a fairly wide range of growth conditions, the film structure depended strongly on the substrate materials and surface orientation and the growth temperature but was insensitive to other growth parameters. In the current work, we systematically studied 
the crystal structures of films grown on single-crystal sapphire $\left(\alpha-\mathrm{Al}_{2} \mathrm{O}_{3}\right)$ substrates with various surface orientations at different growth temperatures. The growth conditions are listed in Table I.

Table I. Growth Conditions

\begin{tabular}{lll}
\hline Total gas flow rate & - & $1300 \mathrm{sccm}$ \\
Reactor pressure & - & $5-20 \mathrm{torr}$ \\
oxygen flow rate & - & $200 \mathrm{sccm}$ \\
OM source temperature & - & $40-65^{\circ} \mathrm{C}$ \\
OM flow rate & - & $10-100 \mathrm{sccm}$ \\
Growth rate & - & $3-150 \AA / \mathrm{min}$ \\
Thickness & - & $300-3000 \AA$ \\
Substrate & - & sapphire $(11 \overline{2} 0),(0001)$, and $(1 \overline{1} 02)$ \\
Growth temperature & - & $400-800^{\circ} \mathrm{C}$ \\
\hline
\end{tabular}

Raman scattering technique was used to characterize the structural phases of the deposited films. The Raman spectra were obtained using an argon ion laser with beam sizes typically 5-10 $\mu \mathrm{m}$ in diameter. This permits us to investigate the structural homogeneity of the films. The crystallographic orientation relationships between the films and the substrates were determined using a four-circle X-ray diffractometer $[7,8]$. The diffractometer was equipped with a rotating anode with $\mathrm{Cu} \mathrm{K \alpha}$ radiation and a bent graphite monochromator. Transmission electron microscopy (TEM) and high resolution electron microscopy (HREM) were used to investigate the film microstructure.

\section{Result and Discussions}

In the early stages of this work when single layer $\mathrm{TiO}_{2}$ films were studied, it was found that very often polycrystalline films with inhomogeneous phases and structures were obtained. The film structure and morphology depended on gas flow velocity, reactor pressure, sample location and susceptor geometry, etc., and the results were often irreproducible. We concluded that this was because of the existence of turbulent flow in the sample region which resulted in mixtures of surface and gas phase reaction products [6]. After optimizing the flow parameters so that turbulence could be completely eliminated, smooth and uniform films were obtained under laminar flow conditions. The flow parameters listed in Table I are well within the range for a laminar flow. Also, in this region, the film structures are only sensitive to the substrate surface and growth temperature.

The crystallinity of the film and the orientation relationship between the film and the substrate were determined using $X$-ray diffraction technique. For example, the $\mathrm{X}$-ray $\theta-2 \theta$ scan data of a $\mathrm{TiO}_{2}$ film grown on sapphire $(1120)$ at $800^{\circ} \mathrm{C}$ is shown in Fig. $1\left(\right.$ a). In addition to the substrate peak $\left(2 \theta=37.77^{\circ}\right)$, a single strong diffraction peak due to the film with $2 \theta=36.12^{\circ}$ is clearly seen in the spectrum. The $2 \theta$ value corresponds well to that of the (101) plane of a rutile crystal [9]. The rocking curve of the growth plane (i.e., $\theta$ scan) as shown in Fig. 1(b) shows a full width at half maximum (FWHM) of $0.18^{\circ}$ indicating a high degree of crystal orientation. In order to determine whether the film was truly epitaxially grown or just highly textured, $\phi$ scans of the (121) plane of the film and the (116) plane of the substrate were carried out and the results are shown in Fig. 1(c). As can be seen, the two curves peak at approximately the same positions (differ by $0.1^{\circ}$ ) which means the $(010)$ plane of the film is parallel to the $(0001)$ plane of the substrate. Also, the $0.46^{\circ}$ of the FWHM indicated the film has a high degree of in-plane epitaxy. Using the same method and procedure described above, we have investigated a number of single-crystal $\mathrm{TiO}_{2}$ or $\mathrm{VO}_{2}$ films grown on sapphire substrates at various growth temperatures. A total of seven distinct epitaxial relationships have been observed and the results can be summarized as follows:

Rutile $\mathrm{TiO}_{2}(101) / /$ sapphire (11̄̄0), Rutile $\mathrm{TiO}_{2}$ (100)//sapphire (1120), Anatase $\mathrm{TiO}_{2}$ (112)//sapphire (0001), Monoclinic $\mathrm{VO}_{2}(010) / /$ sapphire $(1120)$, Monoclinic $\mathrm{VO}_{2}(010)$ //sapphire $(0001)$, Monoclinic $\mathrm{VO}_{2}(100) / /$ sapphire (1120), Monoclinic $\mathrm{VO}_{2}(100) / /$ sapphire (1102),
$(0 \overline{1} 0) / /(0001)$

$(010) / /(0001$

(110)//(1100)

(001)//0001)

$(100 / /(2110)$

$(010) / /(0001)$

$(010) / /(1120)$ 

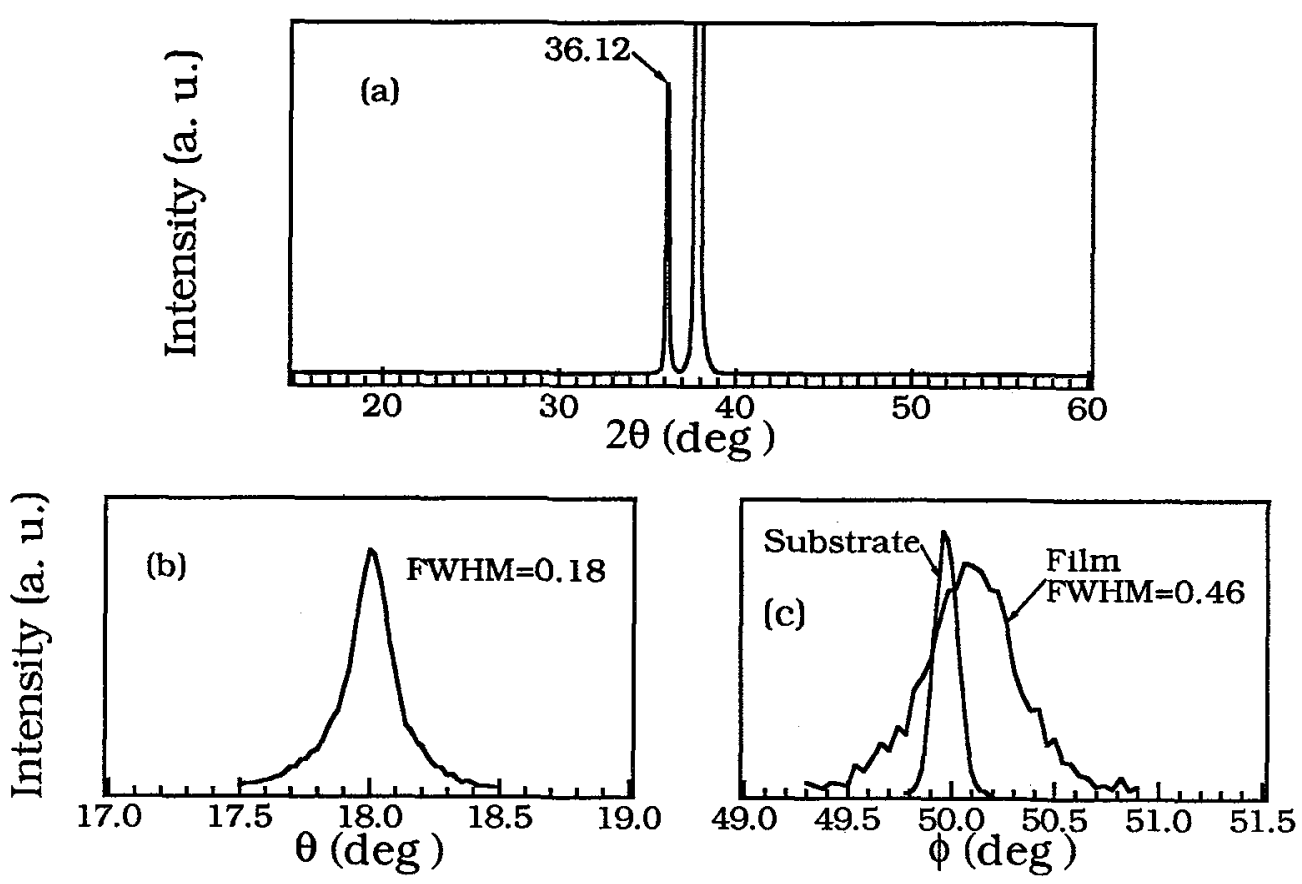

Fig. 1. X-ray diffraction data of a $\mathrm{TiO}_{2}$ film grown on sapphire $\left(11 \overline{2} 0\right.$ ) at $800^{\circ} \mathrm{C}$ : (a) $\mathrm{\theta}-2 \theta$ scan; (b) $\theta$ scan of the film growth plane; (c) $\phi$ scans of the (12) plane of the film and the (116) plane of the substrate.

The film-substrate epitaxial relationship is a function of substrate surface orientation and growth temperature. The functional dependence has been presented elsewhere [10]. For most of the films, the values of the FWHM's of their rocking curves (both $\theta$ and $\phi$ scans) are less than one degree.

It may seem surprising, at first glance, that single-crystal films of $\mathrm{TiO}_{2}$ and $\mathrm{VO}_{2}$ can be obtained on sapphire since the crystal structures of the films and the substrate belong to different lattice systems. The crystal structure is hexagonal for sapphire, tetragonal for rutile and anatase phases of $\mathrm{TiO}_{2}$, and monoclinic or tetragonal for $\mathrm{VO}_{2}[9,11]$. However, further investigation reveals that the atomic arrangements of all these materials are very similar to one another. The oxygen anion arrangements of $\mathrm{TiO}_{2}, \mathrm{VO}_{2}$ and $\alpha-\mathrm{Al}_{2} \mathrm{O}_{3}$ can all be regarded as slightly distorted close-packed structures, and the metal cations occupy the interstices of the close-packed anion network (octahedrally bonded with the six nearest oxygen anion) in different ways for the different materials. Therefore, the epitaxial growth may be viewed as a continuous extension of the anion network from the substrate to the film with the cations arranging differently in the anion interstices.

To further illustrate this point, we have plotted the planar views of the atomic arrangements of the rutile (101), (100), and sapphire (1120) planes in Fig. 2(a), (b), and (c), respectively. We define the normal direction of these planes to be $\mathrm{Z}$-axis with positive direction pointing to the viewer. Cations and anions are represented in the figures by dots and circles, respectively. Plotted in Fig. 2(a) is a layer of titanium cations $(Z=0)$ on top of a layer (corrugated) of distorted close-packed oxygen anions ( $Z$ 's are negative). The corrugated anion layer consists of oxygens represented by different sizes of circles. The larger circles correspond to oxygens that are closer to the top cation layer. Repetition of the two layers in the $\mathrm{Z}$ direction (except for a lateral shift perpendicular to the $\mathrm{Z}$ axis) make up the crystal structure of rutile. The same drawing method has been applied to Fig. 2(b) and (c) except that in (c) the corrugated oxygen layer is drawn on top of the underlying aluminum layer. The lattice unit cells as outlined in the figures do not match each other. But the oxygen patterns of both the rutile (101) and (100) planes are very similar to that of sapphire $(11 \overline{2} 0)$. During the initial layer growth in the deposition process, the titanium atoms 


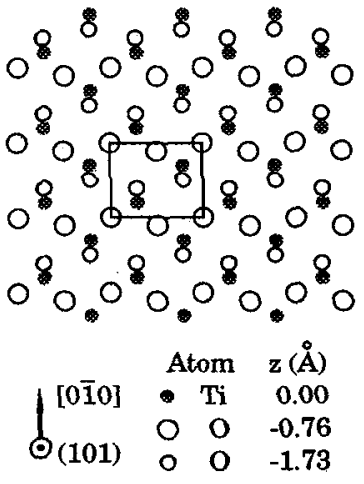

(a)

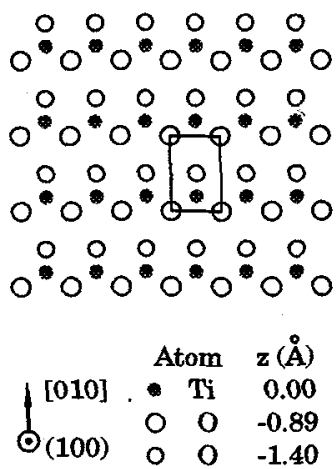

(b)

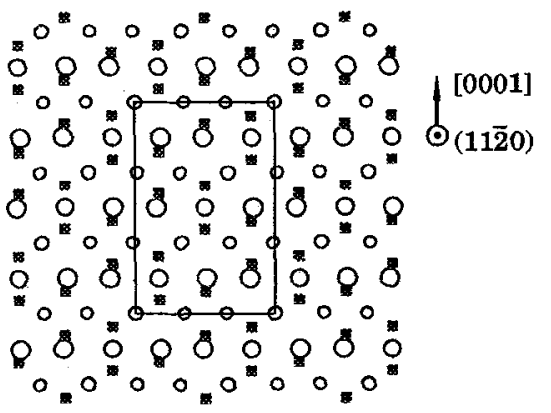

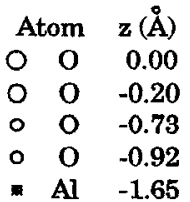

(c)

Fig. 2. The planar views of the atomic arrangements of the (a) rutile (101), (b) rutile (100), and (c) sapphire (1120) planes. The three atomic patterns are drawn to align to one another according to the experimentally observed epitaxial relationships.

or titanium oxygen radicals that were transported from the gas stream to the sapphire surface would "see" an oxygen anion pattern similar to that of rutile (101) or (100) planes. Therefore, a rutile crystal film was formed by way of seeding on an appropriate atomic pattern.

In order to explore this idea further, we have systematically studied the $\mathrm{TiO}_{2}$ films grown on sapphire $(11 \overline{20})$ at temperatures ranging from 400 to $800^{\circ} \mathrm{C}$. At the deposition temperature of $800^{\circ} \mathrm{C}$, the resultant films were always single-crystal rutile with (101) being the growth plane. Figure 3 shows the crosssectional HREM image of a representative sample grown at $800^{\circ} \mathrm{C}$. The $(101) \mathrm{TiO}_{2} /(11 \overline{2} 0) \mathrm{Al}_{2} \mathrm{O}_{3}$ interface shown in Fig. 3(a) is viewed in the direction of $[010]_{R} /[0001]_{S}$ while the same interface viewed in another direction, $[101]_{R} /[1100]_{S}$, is shown in Fig. 3(b). As can be seen, the interface is sharp at the atomic level. The interface is structurally coherent along the direction of $[\overline{101}]_{R} /[1 \overline{100}]_{S}$ (viewed in the direction of $[0 \overline{10}]_{R} /(0001]_{S}$, as shown in Fig. 3(a)) due to the small atomic plane mismatch $(\sim 0.5 \%)$ along this direction. On the other hand, misfit dislocations due to a larger mismatch $(5.9 \%)$ along the $[010]_{R} /[0001]_{S}$ (Fig. 3(b)) direction are periodically observed at the interface. However, these defects at the interface do not seem to distort the crystal structure of the film after only a few monolayers of growth away from the interface. Based on both the X-ray diffraction and HREM results obtained from fifteen samples grown at $800^{\circ} \mathrm{C}$, we found that the (101) plane of rutile is energetically most favorable at this temperature. But as the growth temperature decreases, in addition to (101), grains with $(100)$ growth plane will also nucleate at the interface. This is illustrated in Fig. 4 which shows the cross-sectional HREM image of a rutile film grown at $775^{\circ} \mathrm{C}$. As shown in the figure, microcrystals with (101) as well as (100) growth planes can epitaxially nucleate on the substrate surface at different sites simultaneously, but eventually islands with the (100) growth plane outgrow the other and form a single-crystal (100) film on top of the mixtures at the interface. 
We have also seen films in which the (101) grains outgrow the other resulting in a single-crystal (101) film on top of the mixture region. And yet, in some cases, the two types of grains have comparable growth rates and the resultant films are polycrystalline consisting of the two types of grains throughout the films. This kind of competition between different growth planes has also been observed for $\mathrm{VO}_{2}$ films grown on sapphire (1120). In general, the resultant structures of the films were found to depend on the substrate surface properties (steps, etc.) and the deposition temperature. But the detailed growth mechanism for these phenomena is not yet clear.

(a)

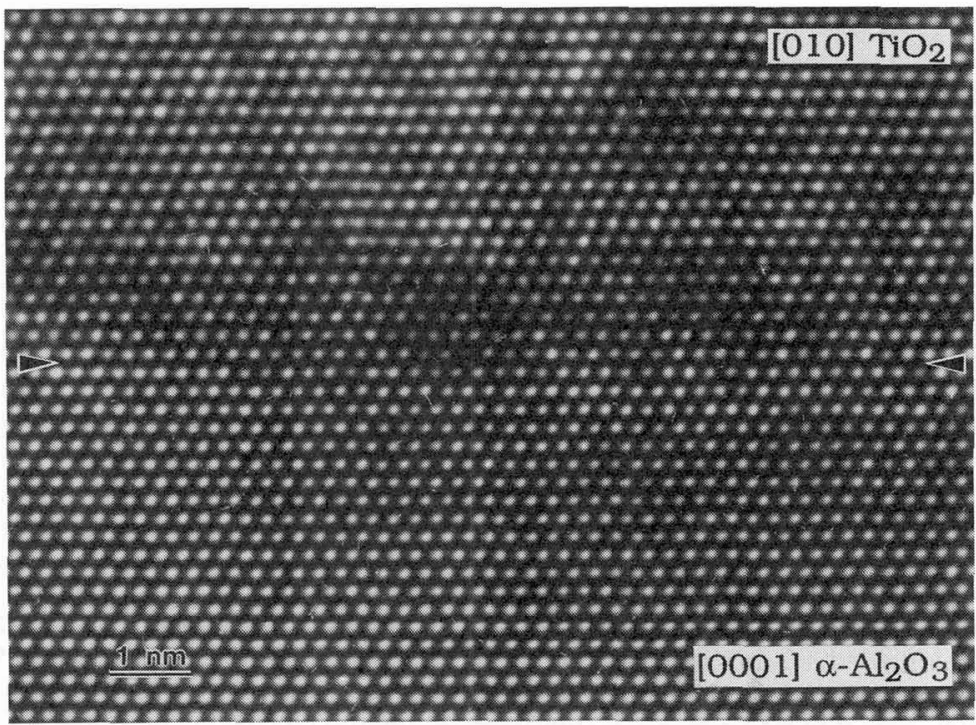

(b)

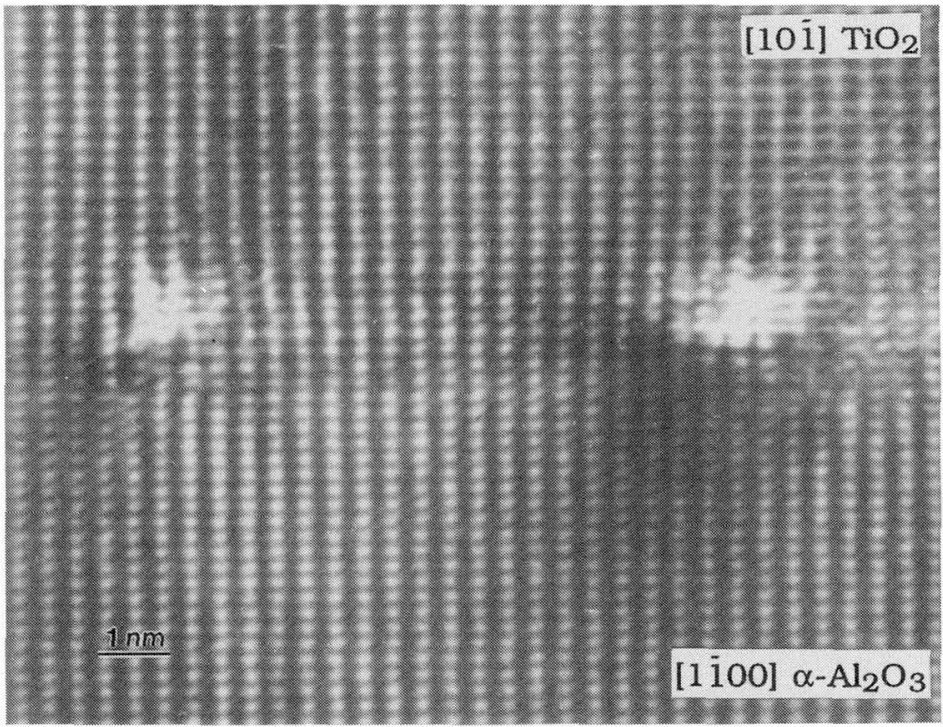

Fig. 3. The cross-sectional HREM image of a rutile $\mathrm{TiO}_{2}$ film grown on sapphire $(1120)$ at $800^{\circ} \mathrm{C}$. The $(101) \mathrm{TiO}_{2} /(1120) \mathrm{Al}_{2} \mathrm{O}_{3}$ interface is viewed in two directions: (a) $[010]_{\mathrm{R}} /[0001]_{S}$, and (b) $\left[101_{R} /[1100]_{S}\right.$. 


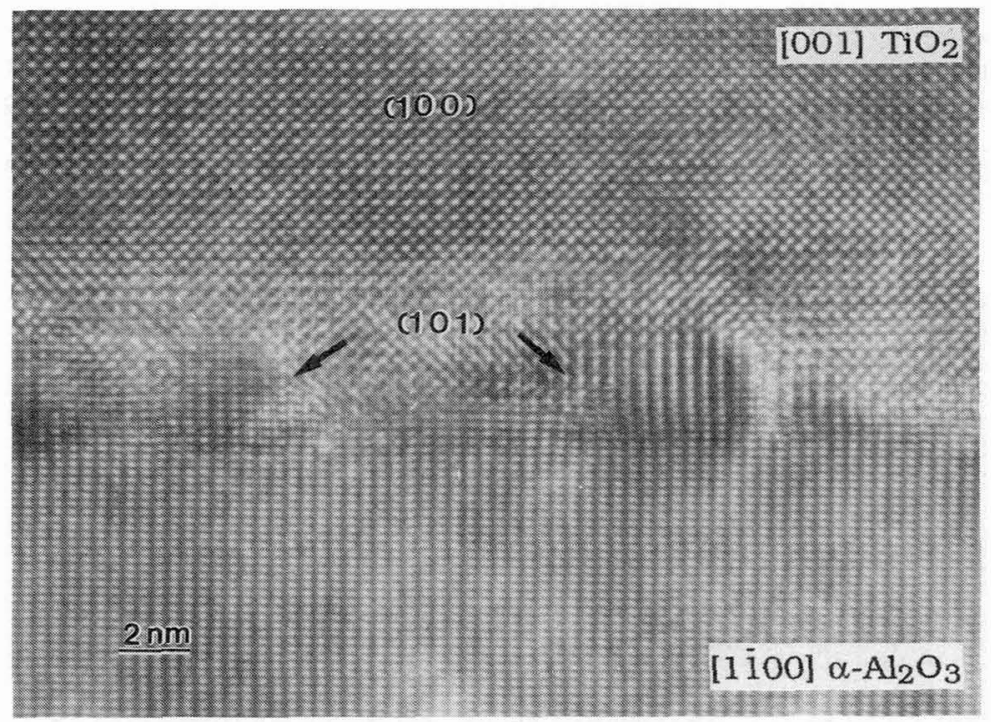

Fig. 4. The cross-sectional HREM image of a rutile film grown on sapphire $(11 \overline{20})$ at $775^{\circ} \mathrm{C}$.

In order to gain an "atomic-level" understanding of the epitaxial relationships observed experimentally and the growth mechanism, we have initiated quantum mechanical calculations of electronic structure, charge distributions and energetics of the substrate surfaces with and without the overlayers. Details of our theoretical approach were given in Ref. [12]. We have calculated electronic structure and charge distributions of sapphire $(11 \overline{2} 0)$ free surfaces with different terminating layers and found that the cleavage surface is the surface terminated with the $O$ layer shown at $-0.73 \AA$ in Fig. 2(c). This result provides a basis for our further understanding of the detailed growth mechanism. The charge density contour diagram on a cross section plane of the cleavage surface is shown in Fig. 5. The plane contains a surface $O$ atoms and two underneath $\mathrm{Al}$ atoms. Details of our theoretical results will be presented elsewhere [13]. Further electronic structure and energetic calculations of the sapphire (1120) cleavage surface with the rutile (101) overlayer are underway.

In addition to single-layer single-crystal films, we have also studied the fabrication of multilayered structures made of $\mathrm{TiO}_{2}$ and $\mathrm{VO}_{2}$. A crystal of $\mathrm{VO}_{2}$ will undergo a structural phase-transition from monoclinic phase to tetragonal phase at approximately $68^{\circ} \mathrm{C}$. The high temperature $\left(>68^{\circ} \mathrm{C}\right)$ tetragonal phase of $\mathrm{VO}_{2}$ has the rutile-type structure and its lattice constants are fairly close to that of rutile $\mathrm{TiO}_{2}[9,11]$. Therefore, one would expect that a single-crystal $\mathrm{VO}_{2}$ film could be grown onto a single-crystal rutile film according to the epitaxial relationships described above. Indeed, this is the case. We have grown $\mathrm{VO}_{2}$ films at $500^{\circ} \mathrm{C}$ on top of $\mathrm{TiO}_{2}$ films which were grown at $800^{\circ} \mathrm{C}$ on sapphire $(1120)$ substrates. Both $\mathrm{TiO}_{2}$ and $\mathrm{VO}_{2}$ film layers were high quality single crystals and the epitaxial relationships are, as expected, as the following: monoclinic $\mathrm{VO}_{2}(100) / /$ rutile (101)//sapphire $(1120) ;(010) / /(010) / /(0001)$. We have also fabricated multilayered films made of alternating layers of $\mathrm{TiO}_{2}$ and $\mathrm{VO}_{2}$. A cross-sectional HREM image of one of the films is shown in Fig. 6. As indicated, the image includes a few layers of $\mathrm{TiO}_{2}$ and $\mathrm{VO}_{2}$ with approximately equal thicknesses $(\sim 30 \AA)$ for each individual layer and the interfaces are perfectly coherent.

\section{Conclusions}

Single-crystal $\mathrm{TiO}_{2}$ and $\mathrm{VO}_{2}$ films in single- and multilayered configurations have been successfully grown on sapphire substrates by the MOCVD technique. In the single-layer configuration, a total of seven distinct epitaxial relationships were observed. By selecting appropriate substrate surface orientations and growth temperatures, we could control the phases (for example, anatase or rutile $\mathrm{TiO}_{2}$ ) and the growth planes of the resultant films. Based on the experimental results, we concluded that single layer films (both $\mathrm{TiO}_{2}$ and $\mathrm{VO}_{2}$ ) were grown by nucleation of three-dimensional clusters and not by the layer-by-layer growth mode. 


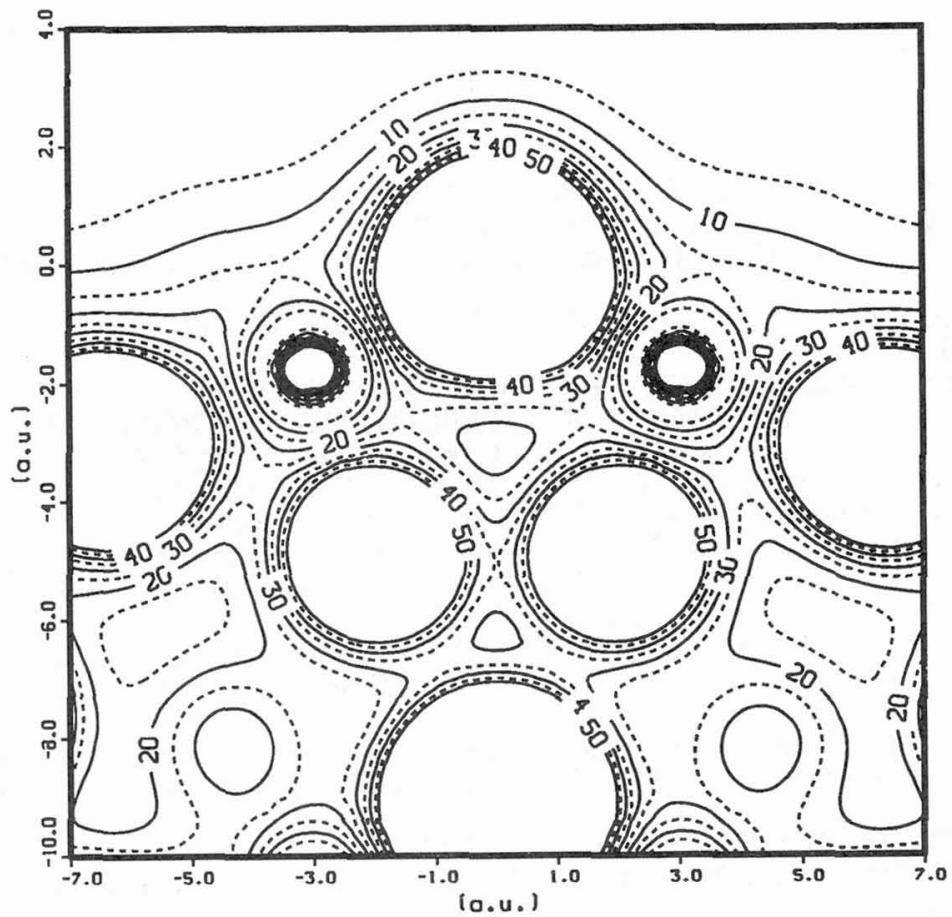

Fig. 5. The charge density contour diagram on a cross section plane of sapphire (1120) cleavage surface. The plane contains a surface $O$ atoms and two underneath $\mathrm{Al}$ atoms. The contour interval is 0.005 a.u. and the maximum contour is 0.05 a.u.

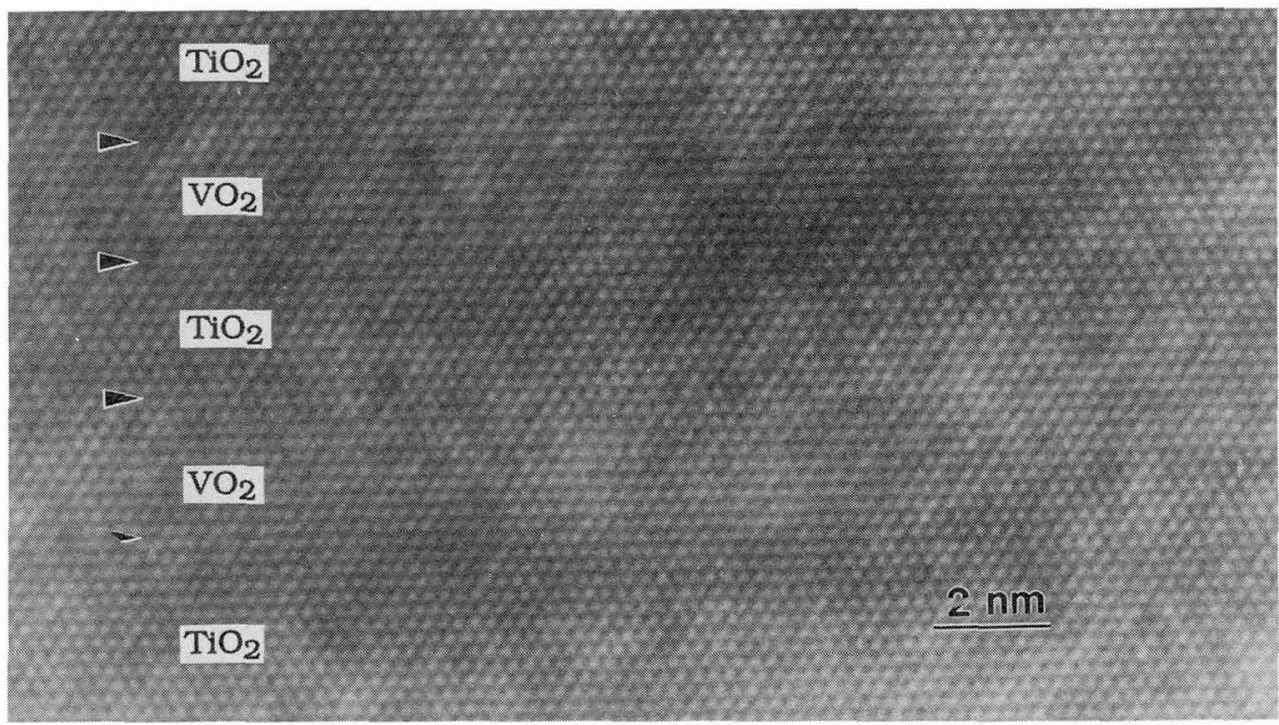

Fig. 6. A cross-sectional HREM image of a multilayered film made of alternating layers of $\mathrm{TiO}_{2}$ and $\mathrm{VO}_{2}$. 


\section{Acknowledgment}

This work was supported by the U.S. Department of Energy, BES-Materials Sciences, under contract \#W-31-109-ENG-38.

\section{References}

1. GOTO, KAZUHIRO SYLVESTER, "Solid State Electrochemistry and Its Applications to Sensors and Electronics Devices" (Elsevier, New York, 1988).

2. RYABOVA, L.A., in: Current Topics in Materials Science, Vol. 7, ed. E. Kaldis (North-Holland, Amsterdam, 1981), Ch. 5.

3. WELLER-BROPHY, L.A., ZELINSKI, B.J.J., and BIRNIE III, D.P., Mater. Res. Soc. Bull. 14(4), 1990, 25.

4. BAUER, E.G., DODSON, B.W., EHRLICH, D.J., FELDMAN, L.C., FLYNN, C.P., GEIS, M.W., HARBISON, J.P., MATYI, R.J., PEERCY, P.S., PETROFF, P.M., PHILLIPS, J.M., STRINGFELLOW, G.B., AND ZANGWILL, A., J. Mater. Res. 5 (1990) 852.

5. CHANG, H.L.M., PARKER, J.C., YOU, H., XU, J.J., and LAM, D.J., in: Chemical Vapor Deposition of Refractory Materials and Ceramics, Mater. Res. Soc. Proc. Vol. 168, eds. T.M. Besmann and B.M. Gallois (Materials Research Society, Pittsburgh, PA, 1990), pp. 343-348.

6. PARKER, J.C., CHANG, H.L.M., XU, J.J., and LAM, D.J., ibid, pp. 337-341.

7. BUSING, W.R. and LEVY, H.A., Acta Cryst. 22 (1967) 457.

8. CHANG, H.L.M., YOU, H., GUO, J., and LAM, D.J., to be published in Appl. Surf. Sci. 1991.

9. HYDE, B.G. and ANDERSON, S., "Inorganic Crystal Structures" (John Wiley \& Sons, New York, 1989).

10. CHANG, H.L.M., YOU, H., PARKER, J.C., GUO, J., GAO, Y., and LAM, D.J., to be published in the Proceedings of the 7 th CIMTEC World Ceramic Congress, Montecatini Terme, Italy, June 2430, 1990.

11. ANDERSSON, G., Acta, Chem. Scand. 10 (1956) 623.

12. ELLIS, D.E., GUO, J., and LAM, D.J., J. Am. Ceram. Soc. 73 (1990) 3231.

13. GUO, J., ELLIS, D.E., and LAM, D.J., to be published. 